Article

\title{
Cyclic Mechanical Behavior of Two Sandy Soils Used as Heat Storage Media
}

\author{
Henok Hailemariam * and Frank Wuttke \\ Geomechanics and Geotechnics Group, Kiel University, Ludewig-Meyn-Straße 10, 24118 Kiel, Germany; \\ frank.wuttke@ifg.uni-kiel.de \\ * Correspondence: henok.hailemariam@ifg.uni-kiel.de
}

Received: 29 June 2020; Accepted: 24 July 2020; Published: 26 July 2020

\begin{abstract}
In this research, the cyclic mechanical behavior of two heat storage sandy soils is experimentally studied using a cyclic thermo-mechanical triaxial device. The results of the tests, which were performed under controlled temperature conditions between 20 and $60{ }^{\circ} \mathrm{C}$, show a significant dependence of the mechanical response of the sandy soils with the amplitude of the cyclic loading and medium temperature. The mechanical performance and accumulation of plastic strains of the soils with an increasing number of loading cycles are discussed in view of the intrinsic soil behavior.
\end{abstract}

Keywords: thermal energy storage; sandy soils; cyclic mechanical loading; temperature

\section{Introduction}

Closing the gap between energy demand and supply is one of the greatest challenges of our time. One of the many practical solutions provided by the field of energy geotechnics in satisfying the worldwide energy demand is via clean and renewable energy schemes, such as seasonal thermal energy storage via borehole thermal energy storage (BTES) systems (e.g., soils) or solid sensible heat storage systems (e.g., cemented porous media). In both cases, heat or cold from solar collectors or other forms of energy is collected and stored for long periods to be used for future industrial or domestic purposes [1-6], and hence such systems have recently emerged as a viable and encouraging alternative in satisfying the energy requirements of both small and large scale applications. A detailed review on the design considerations for BTES systems is provided in [7].

Such sensible thermal energy storage systems are usually built below ground level supporting structures (or designed as part of the sub-structure of buildings) and hence are expected to have load bearing capabilities. Therefore, accurate study of their mechanical stability (both in terms of static and cyclic mechanical loading, due to manmade structures as well as natural hazards such as earthquakes), especially at elevated temperatures, should be carefully assessed prior to their design and operation by performing appropriate mechanical tests.

Several modeling and experimental studies were carried out in the past with regards to the static mechanical behavior of clayey soils at elevated temperatures [8-11]. Uchaipichat and Khalili [12] performed experimental studies on the static mechanical behavior of an unsaturated silt between temperatures of 25 and $60{ }^{\circ} \mathrm{C}$ using a triaxial equipment modified for testing at temperature and suction controlled conditions. Furthermore, an example study of the mechanical stability of solid sensible heat storage materials under the effect of static loading and temperature was presented in [13]. All of the studies showed a significant dependence of the static mechanical performance of the investigated soils/materials on medium temperature. Similar to the response of the soils or other heat storage materials to static loading, their behavior upon cyclic loading is also expected to be affected by changes in temperature. 
Considering the importance of the study of the behavior of soils subjected to cyclic loading, several theoretical and empirical constitutive models to estimate their cyclic behavior have also been proposed in past studies [14-18]. The behavior of clayey soils subjected to cyclic loading has been studied in [19-21]. Cyclic laboratory tests on clayey soils are typically performed in undrained conditions and can lead to the generation of excess pore pressures and the accumulation of shear strains. Several laboratory experiments on the cyclic behavior of sandy soils have also been carried out in the past. Results of cyclic triaxial tests on sand where the increase in the accumulated strains were found to be proportional to the logarithm of the number of cycles were reported in [22]. Other tests where the accumulation of the rate of strain of coarse-grained soils decreased proportionally with the inverse of the number of cycles were reported in [23]. Duku et al. [24] presented the results of drained cyclic tests on sands at various factors such as relative density, gradation, mineralogy, frequency etc., and Tatsuoka et al. [25] reported on the results of undrained cyclic triaxial tests on Toyoura sand at different frequencies between 0.05 and $1.0 \mathrm{~Hz}$. Overall, a negligible influence of the loading frequency on the cyclic behavior of the soils was reported in the literature.

Depending on the drainage type of the granular media used as a heat storage material, the application of a cyclic mechanical loading may cause an accumulation of irreversible or plastic deformations or excess pore pressures. For drained conditions, a cyclic loading can cause the accumulation of plastic strains at a high number of cycles even for small amplitudes of loading. For un-drained conditions, a cyclic loading with a considerably high amplitude (such as from an earthquake) can cause the accumulation of high pore pressures leading to the loss of strength or liquefaction of the soil [14].

Such accumulation of plastic strains is of high importance in practical cases such as in heat storage media, where the tolerance to displacement is small, and may endanger the long-term serviceability of the system. Such serviceability failures within the heat storage granular media can greatly affect the heat transport to and from the soil and the heat exchanger interface. One parameter which is significantly affected by the serviceability failures within the heat storage media is thermal conductivity. The thermal conductivity of the heat storage soils controls the rate of loading or un-loading of heat storage systems and their overall efficiency [26,27].

On this basis, in this study, the cyclic mechanical stability of two heat storage sandy soils was assessed experimentally at different amplitudes of the cyclic loading and temperatures using a cyclic thermo-mechanical triaxial device. The findings of the cyclic loading tests at elevated temperature reported in this study are of particular importance in the context of heat storage soils, especially considering the limited or lack of research available in the literature in this area. The research was conducted as part of the work of project Angus II (Figure 1), which aims at assessing the impacts of the use of the geological subsurface for thermal, electrical and material energy storage in the context of the transition to renewable energy sources, using the area of Schleswig-Holstein, Germany, as a model example. As the soil in the BTES system is near dry condition with a significant hydraulic permeability (porosity), the cyclic loading tests presented in this study were performed at fully drained dry conditions. It should also be noted that unsaturated and dry soils have a lower effective heat capacity when compared to saturated soils, they also possess a comparatively lower effective thermal conductivity, which although it results in lower loading/unloading rates of heat transfer, helps better retention of heat in the storage unit. 


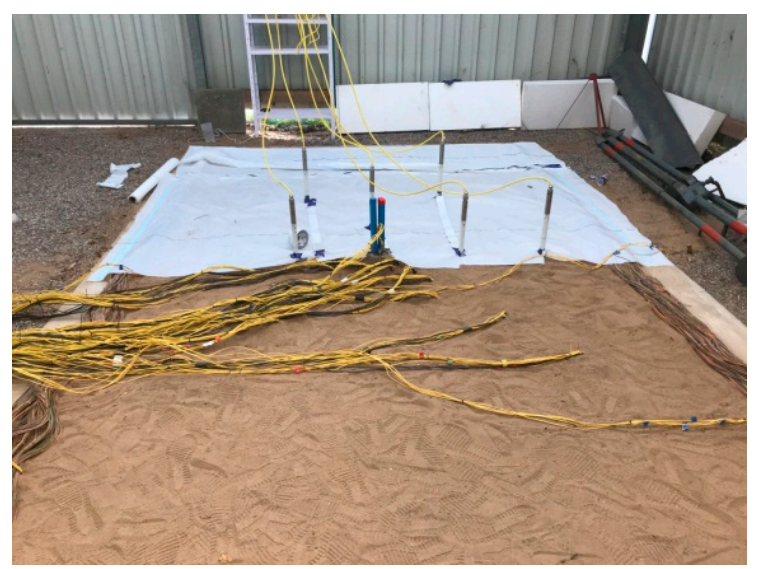

(a)

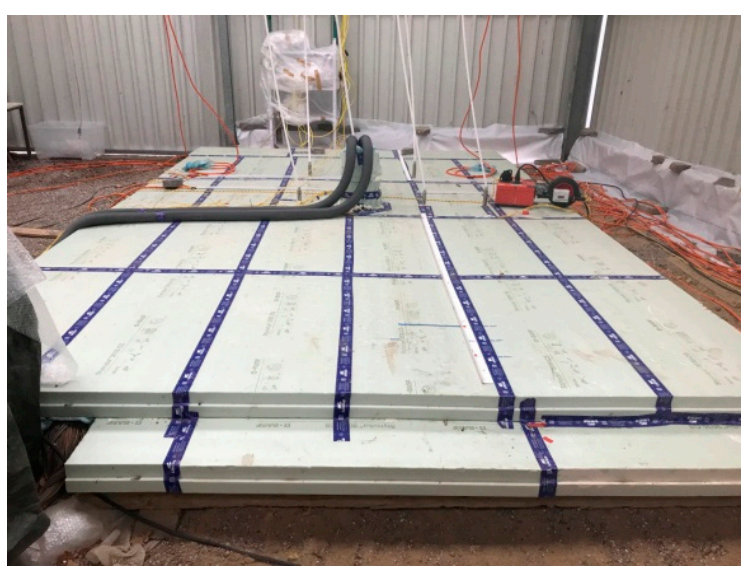

(b)

Figure 1. A meso-scale $5 \times 3 \times 2 \mathrm{~m}^{3}$ experimental indoor high-temperature borehole thermal energy storage (BTES) of project Angus II in Kiel, Germany, with a cemented closed loop borehole heat exchanger (BHE), containing dual u-tube pipes, located at the center of the heat storage system: (a) installation of sensors in the heat storage soil, a fine-sand, which is one of the subjects of investigation of this research; (b) the heat storage system after insulation.

\section{Experimental Program}

\subsection{Tested Soils}

Two coarse-grained soils, namely a fine sand, labeled here as sand A (S-A) (Figure 2a) and a coarse sand, labeled here as sand B (S-B) (Figure 2b) were analyzed.

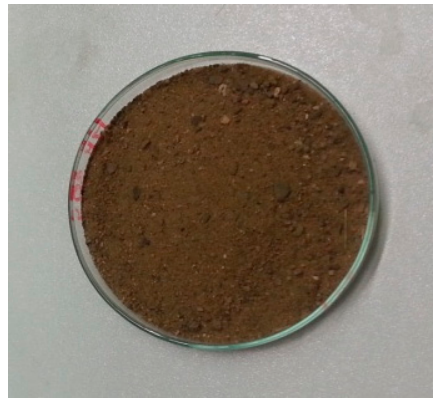

(a)

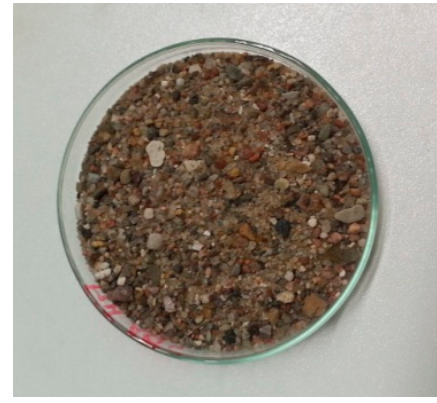

(b)

Figure 2. A sample of: (a) sand A; (b) sand B.

The fine sand, S-A, is also the heat storage media used in the BTES of project Angus II as shown in Figure 1 . Whereas, the coarse sand, S-B, due to its comparatively higher hydraulic permeability, is used for a second set-up in project Angus II as a modular heat storage system, at a comparatively smaller scale, in a cylindrical barrel heated with a central BHE unit to study the convective heat transport in porous media in sensible heat storage systems.

A summary of the obtained physical and geotechnical properties of the sandy soils (obtained through measurements in our laboratories at Kiel University), in accordance with standards [28-30], are presented in Table 1 . The transient effective thermal conductivities and effective heat capacities of the sands were measured using a Decagon KD2 Pro device with a SH-1 dual needle probe, which has a length of $30 \mathrm{~mm}$, a diameter of $1.3 \mathrm{~mm}$ and $6 \mathrm{~mm}$ of spacing between the two needles. The thermal parameter measurements were conducted at room temperature and in atmospheric pressure conditions based on transient line heat source analysis [31,32]. Figures 3 and 4 show the $X$-ray diffraction (XRD) mineralogical analysis and grain size distributions of the soils. 
Table 1. Physical properties of the sandy soils obtained through measurements at Kiel University.

\begin{tabular}{ccc}
\hline Properties & Sand A & Sand B \\
\hline Gravel, $>2 \mathrm{~mm}(\mathrm{wt} . \%)$ & 2.65 & 21.33 \\
Sand, 0.063-2 $\mathrm{mm}(\mathrm{wt} . \%)$ & 95.6 & 78.61 \\
Silt and clay, $<0.063 \mathrm{~mm}(\mathrm{wt} . \%)$ & 1.75 & 0.06 \\
Porosity $n(-)$ & 0.33 & 0.36 \\
Solids specific gravity $G_{S}(-)$ & 2.68 & 2.67 \\
Dry density $\rho_{d}\left(\mathrm{~kg} \mathrm{~m}^{-3}\right)$ & 1790 & 1700 \\
Grain diameter at $10 \%$ passing $D_{10}(\mathrm{~mm})$ & 0.12 & 0.60 \\
Grain diameter at $50 \%$ passing $D_{50}(\mathrm{~mm})$ & 0.33 & 1.20 \\
Coefficient of uniformity $C_{u}(-)$ & 3.33 & 2.17 \\
Coefficient of curvature $C_{\mathcal{c}}(-)$ & 1.30 & 1.28 \\
Dry effective thermal conductivity $\lambda_{d r y}\left(\mathrm{~W} \mathrm{~m}^{-1} \mathrm{~K}^{-1}\right)^{1}$ & 0.309 & 0.295 \\
Saturated eff. thermal conductivity $\lambda_{\text {sat }}\left(\mathrm{W} \mathrm{m}{ }^{-1} \mathrm{~K}^{-1}\right)^{1}$ & 2.188 & 2.054 \\
Dry effective specific heat capacity $c_{d r y}\left(\mathrm{M} \mathrm{J} \mathrm{m}^{-3} \mathrm{~K}^{-1}\right)^{1}$ & 1.355 & 1.269 \\
Saturated eff. specific heat capacity $c_{\text {sat }}\left(\mathrm{M} \mathrm{J} \mathrm{m}^{-3} \mathrm{~K}^{-1}\right)^{1}$ & 2.094 & 2.553 \\
Unified soil classification system $(\mathrm{USCS})$ & $\mathrm{SP}{ }^{2}$ & $\mathrm{SP}{ }^{2}$
\end{tabular}

${ }^{1}$ Effective parameters obtained using Decagon KD2 Pro transient thermal needle probes. ${ }^{2}$ Poorly graded sand.

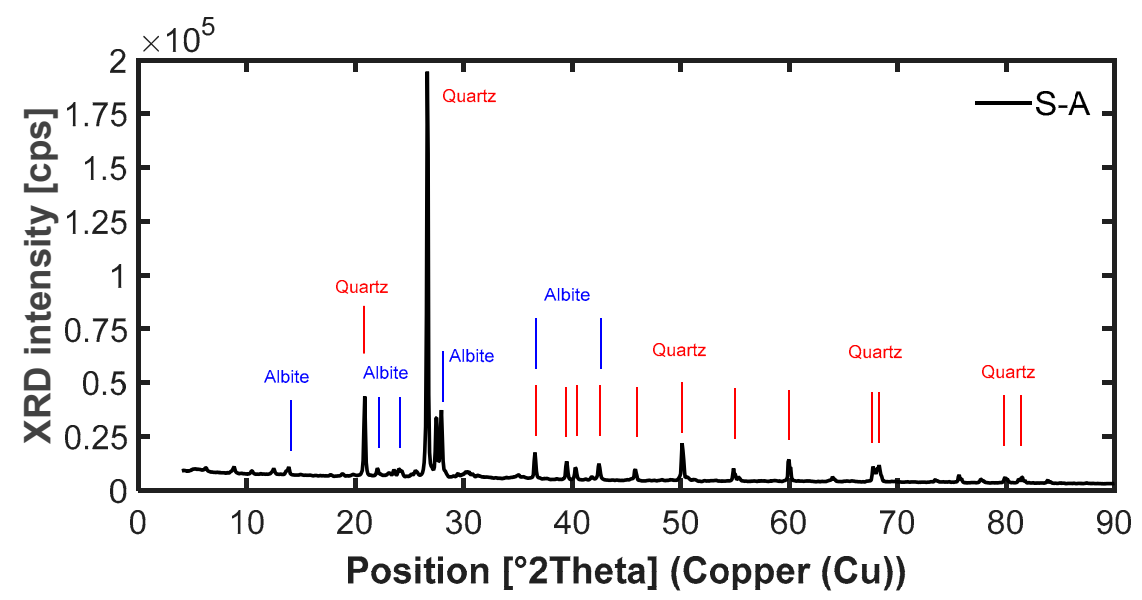

(a)

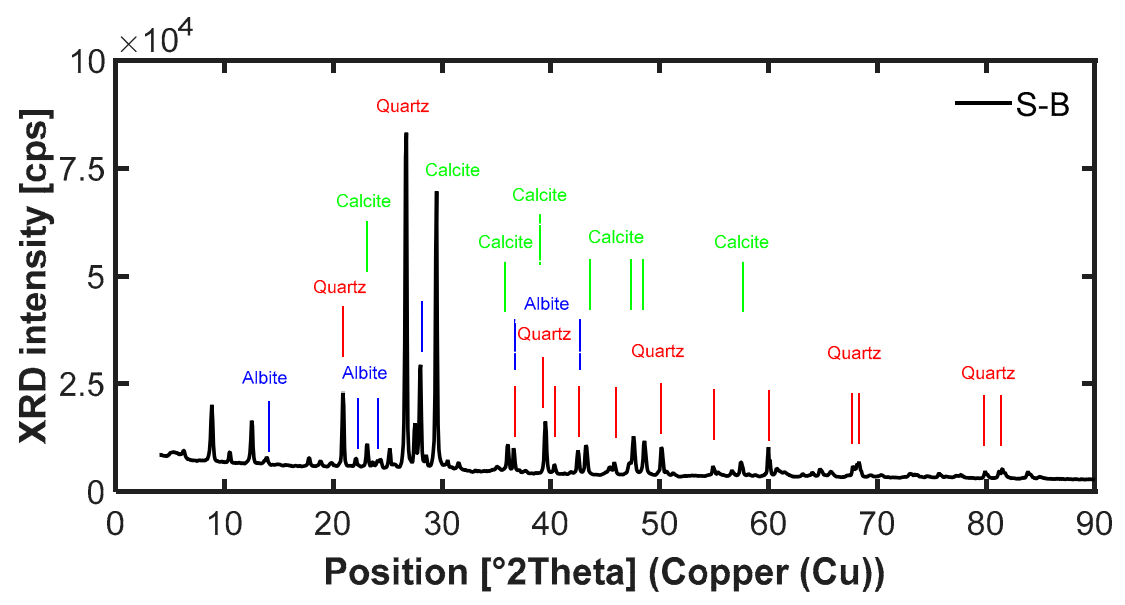

(b)

Figure 3. XRD plots of: (a) sand A; (b) sand B. 


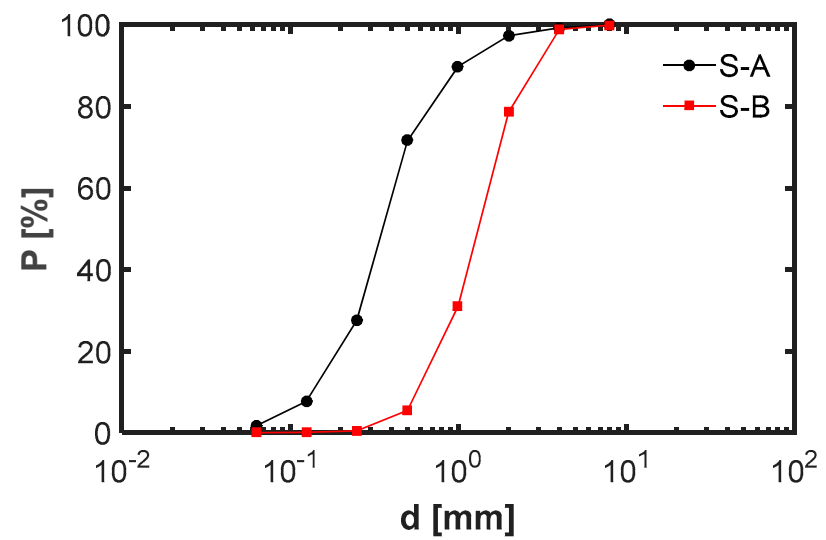

Figure 4. Particle size distributions (percent passing $P$ vs. grain diameter $d$ ) of the two sandy soils.

\subsection{Equipments Used}

The cyclic mechanical stability of the soils was analyzed experimentally using an electromechanical cyclic triaxial testing device (Figures 5 and 6 ). The cyclic testing apparatus consisted of a triaxial cell (Figure 6), a vertical loading machine (with a high precision controlled load frame and a TC4-25 load cell with a maximum force limit of $25 \mathrm{kN}$ ) capable of applying cyclic deviatoric stresses at frequencies $f$ of up to $5 \mathrm{~Hz}$ and different amplitudes, a dynamic high precision cell pressure system capable of applying cyclic cell pressure to the specimen, two WDC dynamic real time digital closed-loop actuator controllers (one for the deviatoric stress and the other for the cell pressure), a single volume-pressure-controller or VPC 10/1000 pore-water (back-pressure) application system (with a volumetric capacity of $1000 \mathrm{ml}$ and maximum pressure limit of $1000 \mathrm{kPa}$ ), a Huber Ministat 125 Pilot ONE heat pump for controlling the temperature of the triaxial cell via a circulating fluid (glycol + distilled water) and a PC control and datalogger unit for system control and data recording (Figure 5).

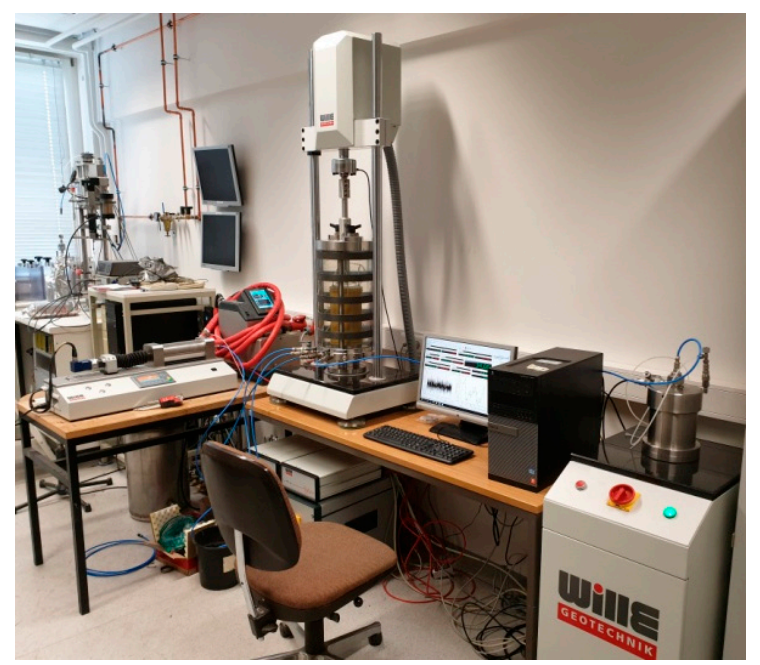

(a)

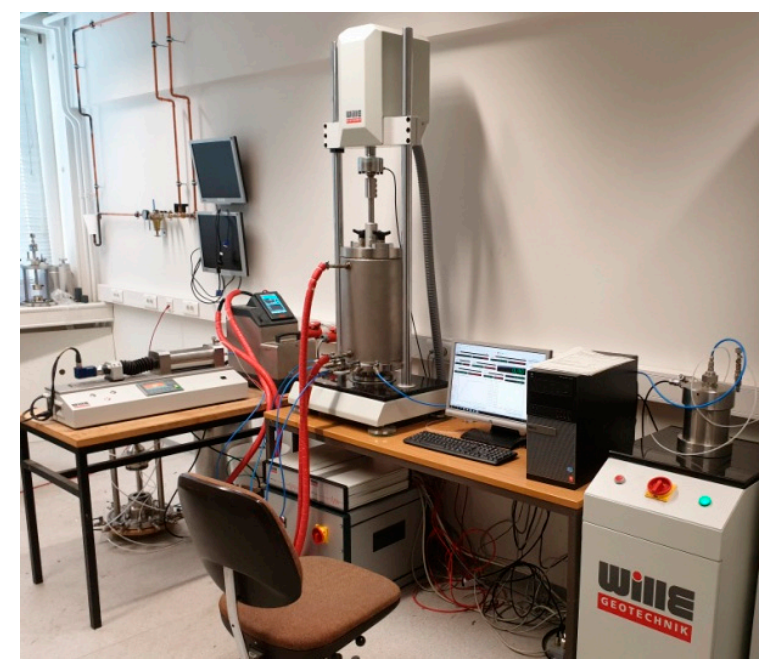

(b)

Figure 5. Cyclic triaxial testing device for (a) room temperature; (b) elevated temperatures. 


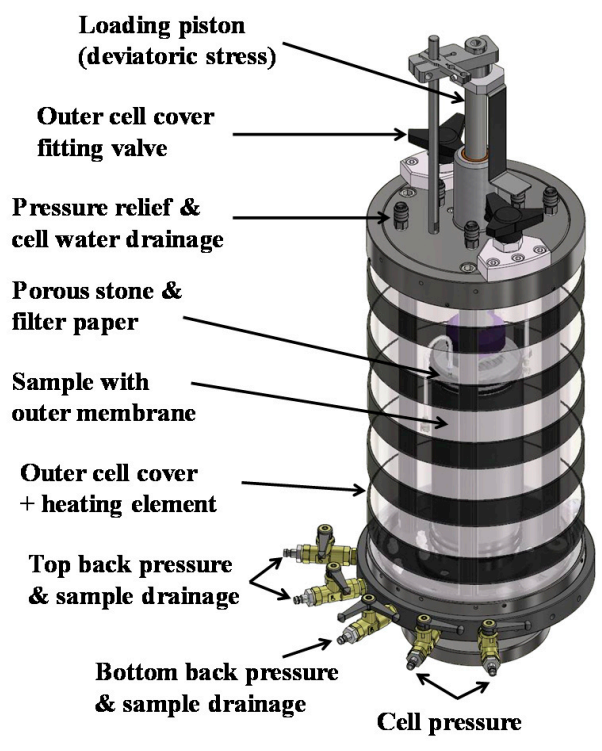

(a)

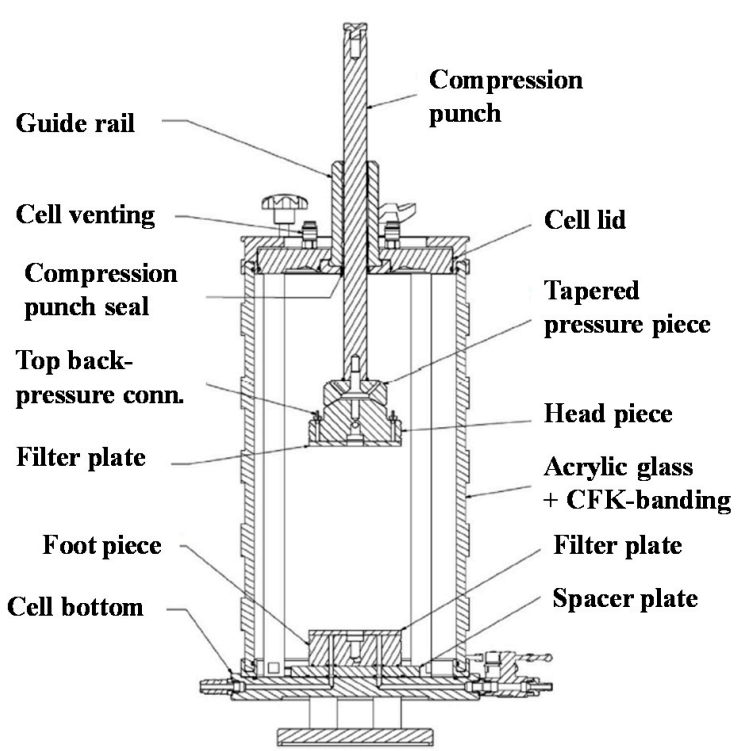

(b)

Figure 6. Schematic representations of the triaxial cell used in testing the sandy soils: (a) outside view; (b) inside or sectional view.

\subsection{Experimental Procedure}

The specimens were prepared at dry moisture condition with a diameter of $100 \mathrm{~mm}$ and a height of $200 \mathrm{~mm}$, making sure that the bulk density was homogeneous throughout the specimen volume. The cyclic loading tests were performed at a cell pressure of $100 \mathrm{kPa}$, which was initially applied to the specimen and was maintained during a short stage consolidation of the samples, during which the drainage valves were kept open and no back pressure was applied. A deviatoric stress $\sigma_{\text {dev }}$ of $150 \mathrm{kPa}$ was then applied statically to the specimens to be used as the base load $\sigma_{\text {dev, base }}$ for the cyclic loading tests, which were conducted with the drainage valves fully open.

The cyclic loading tests were conducted at a frequency $f$ of $0.1 \mathrm{~Hz}$, with deviatoric stress amplitudes $\sigma_{\text {dev, amp }}$ of 10,20 and $30 \mathrm{kPa}$, medium temperatures of 20,40 and $60{ }^{\circ} \mathrm{C}$ and for a number of cycles $N$ of up to a maximum of around 2200. Prior to the start of the cyclic tests, sufficient temperature stabilization time was allotted to achieve steady state conditions within the samples. The cyclic loading and displacement data were recorded at an acquisition rate of around $0.25 \mathrm{~s}$. The mechanical (static and cyclic) loading schemes used are diagrammatically depicted in Figure 7.

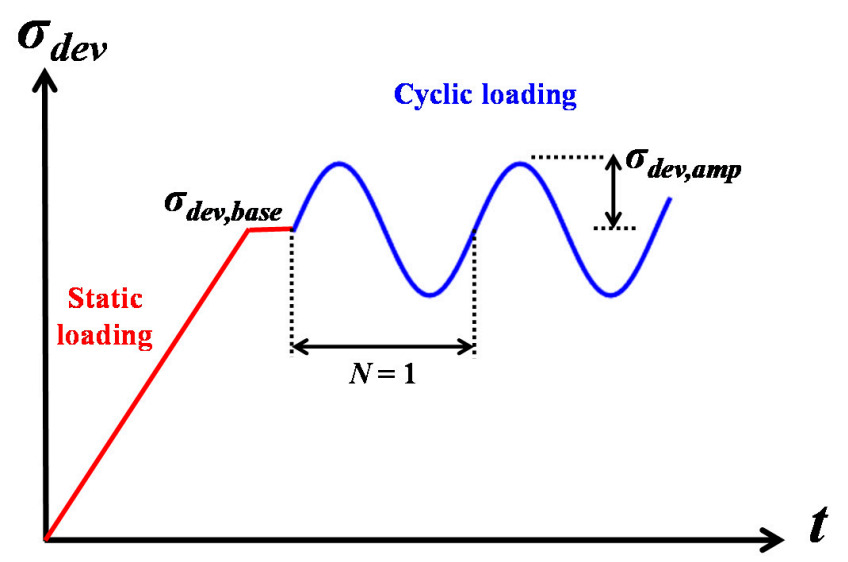

Figure 7. Schematic representation of the loading schemes used for testing the soils. 


\section{Results and Discussion}

\subsection{Time Plots}

Figure 8 presents the time plot results for the first three cycles of the cyclic loading tests of the sandy soils at room temperature.

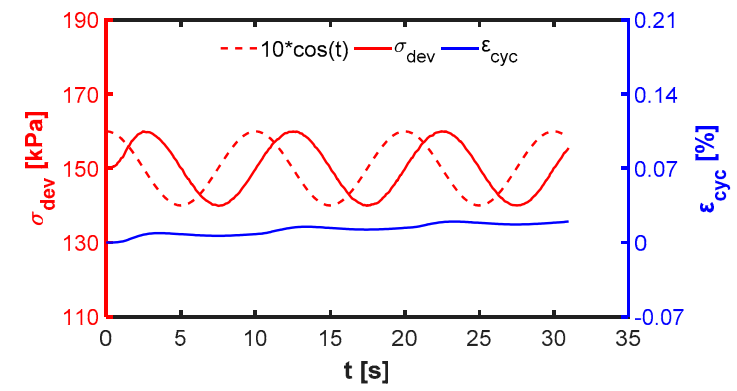

(a)

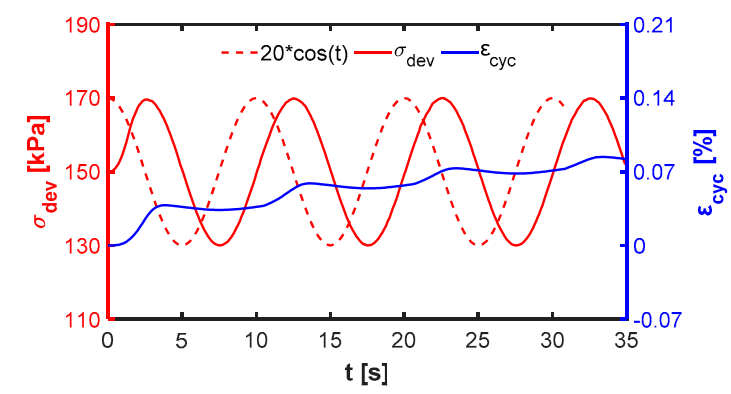

(c)

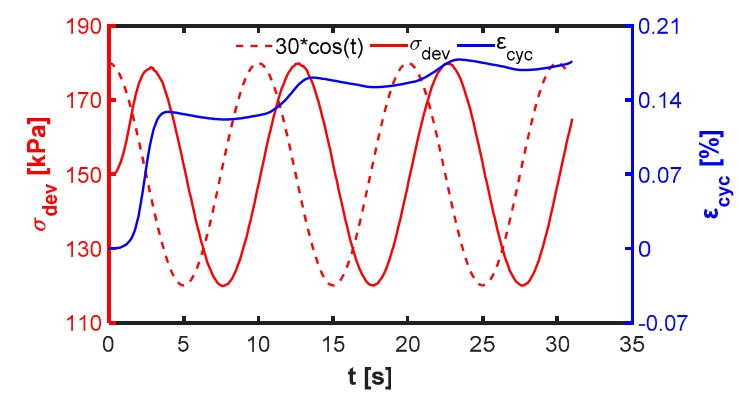

(e)

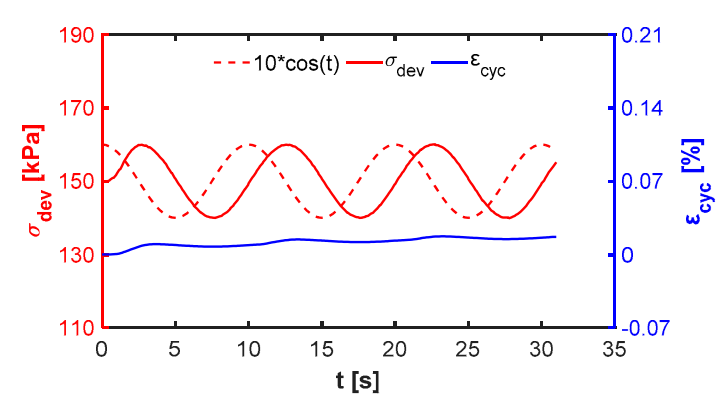

(b)

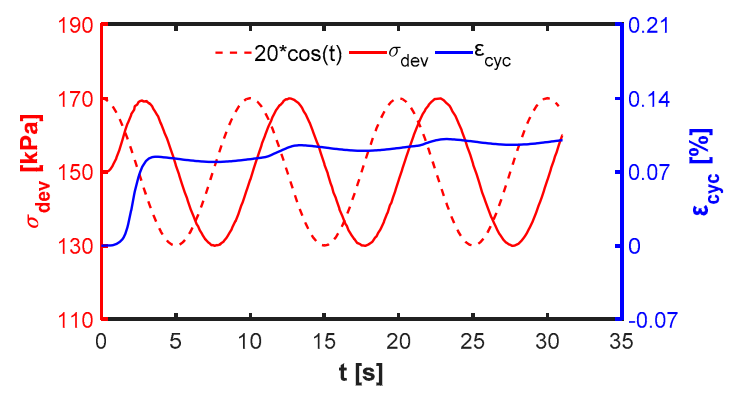

(d)

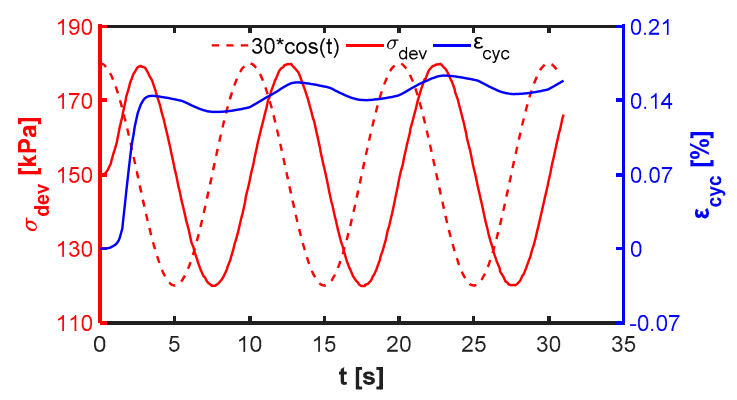

$(\mathbf{f})$

Figure 8. Cyclic loading time plots with deviatoric stress amplitudes $\sigma_{\text {dev }, a m p}$ of 10,20 and $30 \mathrm{kPa}$ for $(\mathbf{a}, \mathbf{c}, \mathbf{e})$ sand $\mathrm{A} ;(\mathbf{b}, \mathbf{d}, \mathbf{f})$ sand $\mathrm{B}$.

The plots showed a significant increase in the measured axial cyclic strain $\varepsilon_{c y c}$ of the soil samples with the increasing number of cycles $N$, as the strain and stress loops generated due to the application of the cyclic loads were not completely closed. This led to irrecoverable strains and the accumulation of plastic strain $\varepsilon_{a c c}$ with each applied cycle [14]. As the frequency $f$ of the cyclic loading in this study was in between 0 and $1 \mathrm{~Hz}$, inertia forces could be neglected and the accumulated strains were predominantly plastic $[33,34]$.

Moreover, the magnitude of the $\varepsilon_{a c c}$ of the soils was generally the highest within the first cycle, which is commonly referred to as the "irregular cycle". As expected, for both soils, the magnitudes of the $\varepsilon_{a c c}$ increased with an increase in the applied deviatoric stress amplitude $\sigma_{d e v, a m p}$ or cyclic strain amplitude, corroborating previous studies [14,24]. 


\subsection{Cyclic Loading Results at Different Deviatoric Stress Amplitudes}

Figures 9 and 10 show the results of the cyclic loading tests on the soils which were conducted at room temperature with deviatoric stress amplitudes $\sigma_{\text {dev,amp }}$ between 10 and $30 \mathrm{kPa}$.

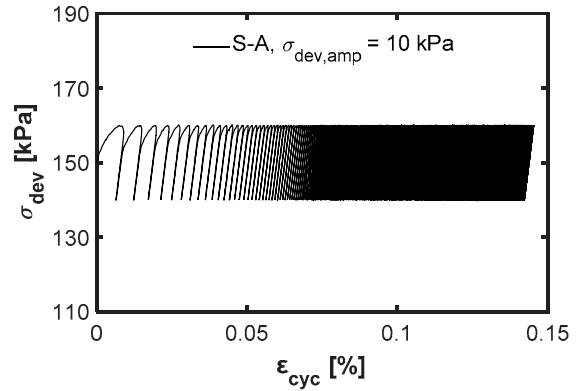

(a)

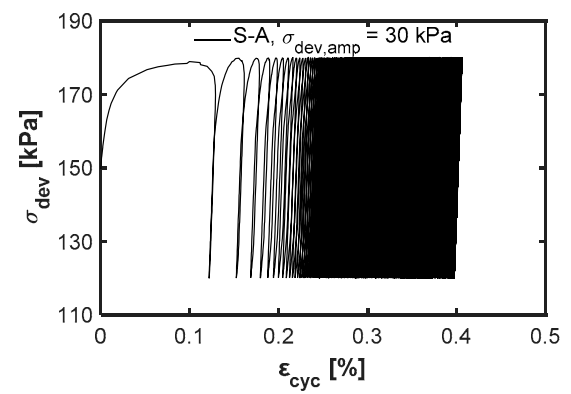

(c)

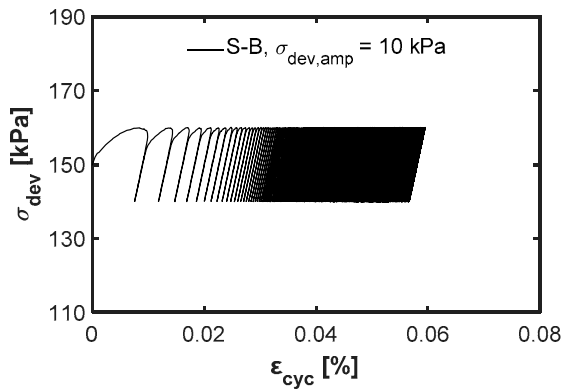

(b)

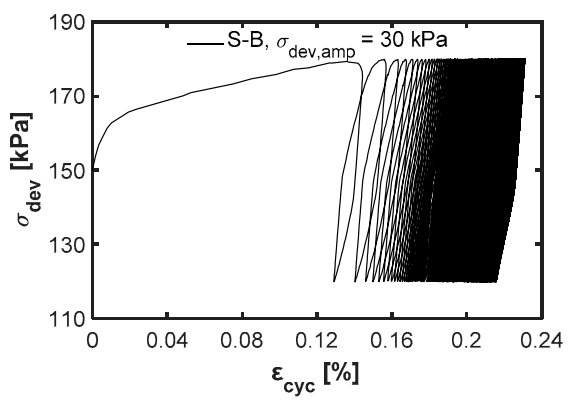

(d)

Figure 9. Cyclic stress-strain plots at room temperature with deviatoric stress amplitudes $\sigma_{\text {dev,amp }}$ of 10 and $30 \mathrm{kPa}$ for $(\mathbf{a}, \mathbf{c})$ sand $\mathrm{A} ;(\mathbf{b}, \mathbf{d})$ sand $\mathrm{B}$.

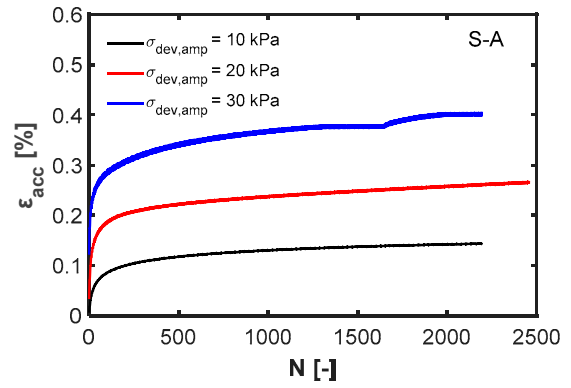

(a)

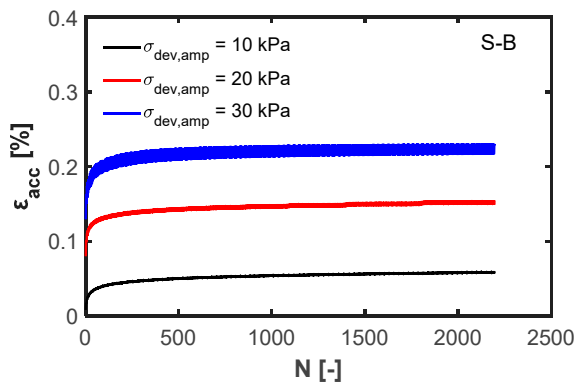

(b)

Figure 10. Accumulated plastic strain $\varepsilon_{a c c}$ vs. number of cycles $N$ plots at room temperature and with different deviatoric stress amplitudes $\sigma_{\text {dev, amp }}$ for (a) sand A; (b) sand B.

The results showed a significant increase in the measured axial cyclic strains $\varepsilon_{c y c}$ and hence the accumulation of plastic strains $\varepsilon_{a c c}$ of both soils with the increasing number of cycles $N$. The rate of increase in the measured $\varepsilon_{a c c}$ of the soils was also directly proportional to the magnitudes of the applied deviatoric stress amplitudes $\sigma_{\text {dev, amp }}[14,24]$. With the application of cyclic loading and changes in the stress-strain loops of the soils, the quartz and albite dominated particle grains (grains of high angular shape irregularity and hence interlocking, especially for sand B as shown in Figure 2, and with a high uniformity of particle gradation leading to high soil void ratios as shown in Table 1 and Figure 4) were subjected to changes in their inter-particle interlocking and frictional forces and the soil skeleton underwent grain rearrangements leading to irrecoverable or plastic strains. 
Moreover, most of the measured $\varepsilon_{a c c}$ of the soils occurred within the first 100 cycles, after which the increase in the measured $\varepsilon_{a c c}$ was gradual. When comparing the nature of the accumulation of plastic strain of the soils due to cyclic loading with previous studies, it can be concluded that they exhibited a typical shakedown behavior, where the strain increment decreases with the increasing number of cycles without reaching ultimate failure [34,35]. Overall, sand $\mathrm{A}$ had higher recorded $\varepsilon_{c y c}$ and $\varepsilon_{a c c}$ values for the given number of cycles when compared with sand $\mathrm{B}$ (with $\varepsilon_{a c c}$ values of $0.4 \%$ for sand $\mathrm{A}$ and $0.22 \%$ for sand $\mathrm{B}$ at around $N=2200$ cycles for $\sigma_{\text {dev,amp }}$ of $30 \mathrm{kPa}$ at room temperature), due to its comparatively finer texture and lower strength or compressibility modulus.

With the application of cyclic mechanical loading and the subsequent increase in the accumulated plastic strains and hence the compaction of soils, the effective thermal conductivity of soils is expected to increase. This will in turn maximize the efficiency of the heat storage system by increasing the charging/un-charging rates of the heat storage unit. However, cyclic mechanical loading may have a negative impact on the BHE unit of the heat storage system (which is usually made of cemented porous media) by creating serviceability failures/formation of cracks with an increase in the number of cycles and the accumulation of plastic strains, which will in turn lower the effective thermal conductivity and hence the efficiency of heat transfer of the cemented media.

\subsection{Cyclic Loading Results at Different Temperatures}

Figures 11 and 12 show the results of the cyclic loading tests which were conducted with a deviatoric stress amplitude $\sigma_{\text {dev, amp }}$ of $20 \mathrm{kPa}$ and medium temperatures $\mathrm{T}$ between 20 and $60^{\circ} \mathrm{C}$.

As can be seen from the results, for the given deviatoric stress amplitude $\sigma_{d e v, a m p}$, an increase in temperature $T$ of the soils introduced elastic behavior in the soil skeleton, which allowed for the recovery of a small portion of the total cyclic strain $\varepsilon_{c y c}$ of each cycle (see the stress-strain loops and stiffness changes within each cycle as depicted in Figure 11). As a result, a more stable soil configuration with a comparatively lower measured $\varepsilon_{a c c}$ was obtained with an increase in the medium temperature of both sands. This reduction in the measured $\varepsilon_{a c c}$ of the soils at elevated temperatures may mitigate some of the effects of the long term serviceability failures typically caused by the accumulation of plastic strains due to cyclic loading, which can in turn cause significant reductions to the effective thermal conductivity of the heat storage materialsin the BTES system.

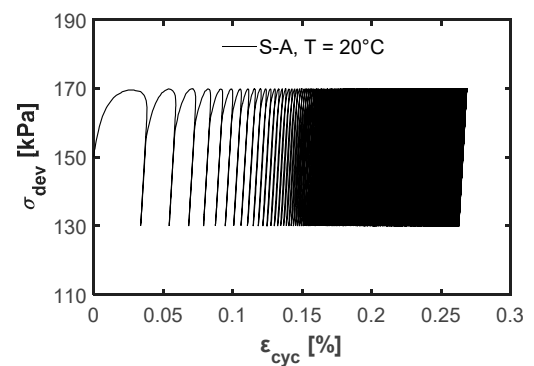

(a)

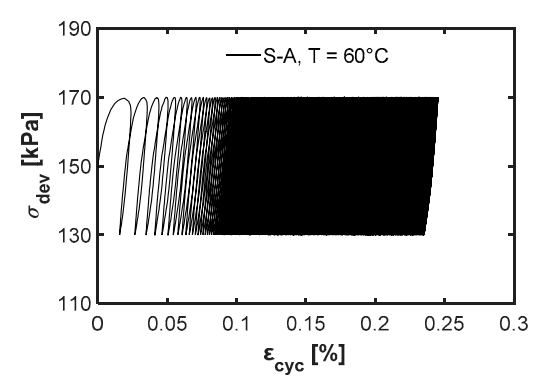

(c)

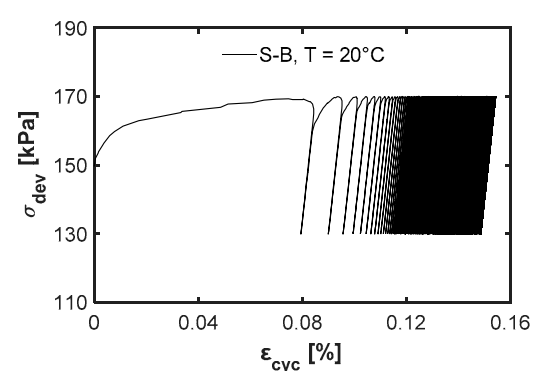

(b)

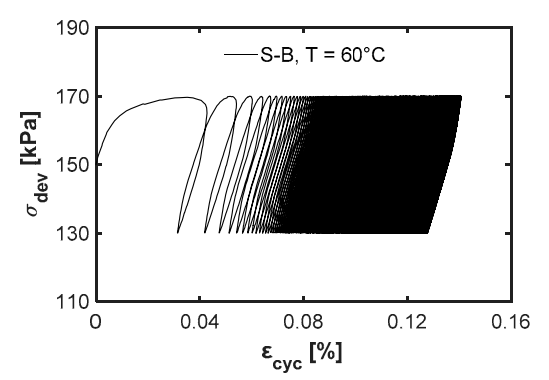

(d)

Figure 11. Cyclic stress-strain plots with temperatures of 20 and $60^{\circ} \mathrm{C}$ for $(\mathbf{a}, \mathbf{c})$ sand $\mathrm{A} ;(\mathbf{b}, \mathbf{d})$ sand $\mathrm{B}$. 


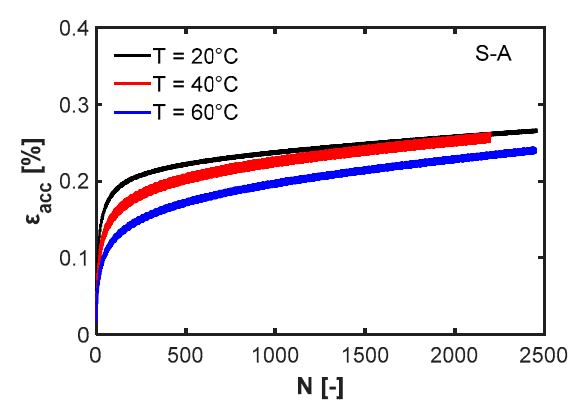

(a)

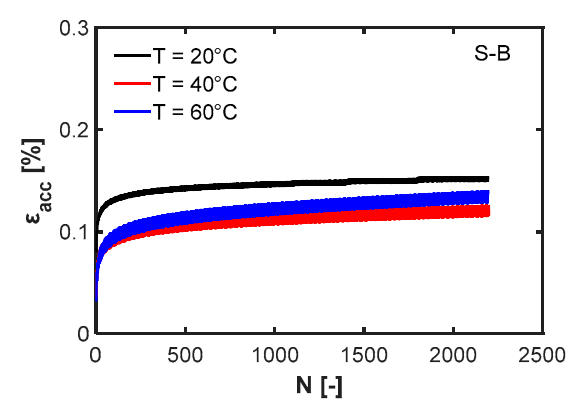

(b)

Figure 12. Accumulated plastic strain $\varepsilon_{a c c}$ vs. number of cycles $N$ plots at different temperatures $T$ for (a) sand A; (b) sand B.

\section{Conclusions}

Assessing the mechanical behavior (in the forms of static and cyclic loading, from manmade structures as well as natural hazards such as earthquakes) of heat storage media in solid sensible heat storage and borehole thermal energy storage (BTES) systems is essential prior to their design and operation, as such systems are usually designed at or below ground level with load bearing capabilities and supporting structures. Furthermore, for the case of cyclic mechanical loading, the accurate estimation of the accumulated plastic strains of the heat storage material prior to the design of the heat storage system ensures the avoidance of future long-term serviceability failures. In this study, the cyclic mechanical performance of two heat storage sandy soils was experimentally studied using a cyclic thermo-mechanical triaxial device.

The results showed a significant increase in the measured axial cyclic strains and the accumulation of plastic strains of both soils with the increasing number of cycles. As expected, the rate of increase in the measured accumulated plastic strains of the soils was also found to be directly proportional to the magnitudes of the applied deviatoric stress amplitudes. Moreover, most of the measured accumulated plastic strains of the soils occurred within the first 100 cycles, after which the increase in the accumulated plastic strains wasgradual. Overall, sand A exhibited higher recorded axial cyclic strains and accumulated plastic strains for the given number of cycles when compared with sand B (with accumulated plastic strains of $0.4 \%$ for sand $\mathrm{A}$ and $0.22 \%$ for sand $\mathrm{B}$ at around 2200 cycles for a cyclic loading deviatoric amplitude of $30 \mathrm{kPa}$ at room temperature), due to its comparatively finer texture and lower strength or compressibility modulus.

Furthermore, an increase in the temperature of the soils introduced elastic behavior in the quartz and albite dominated soil skeleton, which allowed for the recovery of a small portion of the total cyclic strain within each cycle, leading to a more stable soil configuration with a comparatively lower accumulation of plastic strains. Overall, the results show a significant dependence of the cyclic mechanical behavior, and in particular the accumulation of plastic strains, of the investigated heat storage sandy soils on the amplitude of the applied cyclic loading and the medium temperature.

Author Contributions: Conceptualization, H.H.; methodology, H.H.; software, H.H.; validation, H.H.; formal analysis, H.H.; investigation, H.H.; resources, H.H. and F.W.; data curation, H.H.; writing-original draft preparation, H.H.; writing - review and editing, H.H. and F.W.; visualization, H.H.; project administration, F.W.; funding acquisition, F.W. All authors have read and agreed to the published version of the manuscript.

Funding: This research was supported by the German Federal Ministry for Economic Affairs and Energy (BMWi), grant number 03ET6122A (Project ANGUS II).

Acknowledgments: The authors would like to acknowledge the support of Jülich for project managing. We thank Paul Liedtke, formerly of Kiel University, for kindly providing us with the field test images shown in Figure 1, and APS Antriebs-, Prüf- und Steuertechnik GmbH, Rosdorf, Germany, for kindly providing us with the raw images for the schematic diagrams of the triaxial cell shown in Figure 6. We would also like to thank Kerstin Meier zu Beerentrup of Kiel University for her support in analyzing the XRD measurements. 
Conflicts of Interest: The authors declare no conflict of interest. The funders had no role in the design of the study; in the collection, analyses or interpretation of data; in the writing of the manuscript; or in the decision to publish the results.

\section{References}

1. Laing, D.; Steinmann, W.-D.; Tamme, R.; Richter, C. Solid media thermal storage for parabolic trough power plants. Sol. Energy 2006, 80, 1283-1289. [CrossRef]

2. Bauer, D.; Marx, R.; Nußbicker-Lux, J.; Ochs, F.; Heidemann, W.; Müller-Steinhagen, H. German central solar heating plants with seasonal heat storage. Sol. Energy 2010, 84, 612-623. [CrossRef]

3. Marx, R.; Nußbicker-Lux, J.; Bauer, D.; Heidemann, W.; Drück, H. Saisonale Wärmespeicher-Bauarten, Betriebsweise und Anwendungen. Chem. Ing. Tech. 2011, 83, 1994-2001. [CrossRef]

4. Laing, D.; Bahl, C.; Bauer, T.; Fiss, M.; Breidenbach, N.; Hempel, M. High-temperature solid-media thermal energy storage for solar thermal power plants. Proc. IEEE 2012, 100, 516-524. [CrossRef]

5. Sibbitt, B.; McClenahan, D.; Djebbar, R.; Thornton, J.; Wong, B.; Carriere, J.; Kokko, J. The performance of a high solar fraction seasonal storage district heating system - five years of operation. Energy Procedia 2012, 30, 856-865. [CrossRef]

6. Başer, T.; McCartney, J.S. Transient evaluation of a soil-borehole thermal energy storage system. Renew. Energy 2020, 147, 2582-2598. [CrossRef]

7. Skarphagen, H.; Banks, D.; Frengstad, B.S.; Gether, H. Design considerations for borehole thermal energy storage (BTES): A review with emphasis on convective heat transfer. Geofluids 2019, 4961781, 1-26. [CrossRef]

8. Cui, Y.J.; Sultan, N.; Delage, P. A thermomechanical model for saturated clays. Can. Geotech. J. 2000, 37, 607-620. [CrossRef]

9. Burghignoli, A.; Desideri, A.; Miliziano, S. A laboratory study on the thermomechanical behaviour of clayey soils. Can. Geotech. J. 2000, 37, 764-780. [CrossRef]

10. Abuel-Naga, H.M.; Bergado, D.T.; Lim, B.F. Effect of temperature on shear strength and yielding behavior of soft Bangkok clay. Soils Found. 2007, 47, 423-436. [CrossRef]

11. Hueckel, T.; François, B.; Laloui, L. Explaining thermal failure in saturated clays. Géotechnique 2009, 59, 197-212. [CrossRef]

12. Uchaipichat, A.; Khalili, N. Experimental investigation of thermo-hydro-mechanical behaviour of an unsaturated silt. Géotechnique 2009, 59, 339-353. [CrossRef]

13. Hailemariam, H.; Schwindrofska, D.; Wuttke, F. Mechanical stability of cemented porous heat storage media. In Geotechnical Engineering in the XXI Century: Lessons learned and future challenges, Proceedings of the XVI Pan American Conference on Soil Mechanics and Geotechnical Engineering, Cancún, Mexico, 17-20 November 2019; López-Acosta, N.P., Martínez-Hernández, E., Espinosa-Santiago, A.L., Mendoza-Promotor, J.A., Ossa López, A., Eds.; IOS Press: Amsterdam, The Netherlands, 2019; pp. $2867-2872$.

14. Sawicki, A.; Swidzinski, W. Mechanics of a sandy subsoil subjected to cyclic loadings. Int. J. Numer. Anal. Methods Geomech. 1989, 13, 511-529. [CrossRef]

15. Zienkiewicz, O.C.; Chang, C.T.; Hinton, E. Non-linear seismic response and liquefaction. Int. J. Numer. Anal. Methods Geomech. 1978, 2, 381-404. [CrossRef]

16. Finn, W.D.L. Dynamic response analyses of saturated sands. In Soil Mechanics-Transient and Cyclic Loads; Zienkiewicz, O.C., Ed.; Wiley: New York, NY, USA, 1982.

17. Ni, J.; Indraratna, B.; Geng, X.-Y.; Carter, J.P.; Chen, Y.-L. Model of soft soils under cyclic loading. Int. J. Geomech. 2014, 04014067, 1-10. [CrossRef]

18. Khasawneh, Y.; Bobet, A.; Frosch, R. A simple soil model for low frequency cyclic loading. Comput. Geotech. 2017, 84, 225-237. [CrossRef]

19. Vucetic, M. Cyclic threshold shear strains in soils. J. Geotech. Eng. ASCE 1994, 120, 2208-2228. [CrossRef]

20. Hsu, C.C.; Vucetic, M. Threshold shear strain for cyclic pore-water pressure in cohesive soils. J. Geotech. Geoenvironmental Eng. ASCE 2006, 132, 1325-1335. [CrossRef]

21. Ichii, K.; Mikami, T. Cyclic threshold shear strain in pore water pressure generation in clay in situ samples. Soils Found. 2018, 58, 756-765. [CrossRef] 
22. Lentz, R.W.; Baladi, G.Y. Simplified procedure to characterize permanent strain in sand subjected to cyclic loading. In International Symposium on Soils under Cyclic and Transient Loading, Swansea, UK, 7-11 January 1980; Balkema: Rotterdam, The Netherlands, 1980; pp. 89-95.

23. Suiker, A.S.G. Static and Cyclic Loading Experiments on Non Cohesive Granular Materials; Report No. 1-99-DUT-1; TU Delft: Mekelweg, The Netherlands, 1999.

24. Duku, P.M.; Stewart, J.P.; Whang, D.H.; Yee, E. Volumetric strains of clean sands subject to cyclic loads. J. Geotech. Geoenviron. Eng. ASCE 2008, 134, 1073-1085. [CrossRef]

25. Tatsuoka, F.; Toki, S.; Miura, S.; Kato, H.; Okamoto, M.; Yamada, S.-I.; Yasuda, S.; Tanizawa, F. Some factors affecting cyclic undrained triaxial strength of sand. Soils Found. 1986, 26, 99-116. [CrossRef]

26. Doughty, C.; Nir, A.; Tsang, C.F.; Bodvarsson, G.S. Heat storage in unsaturated soils: Initial theoretical analysis of storage design and operational method. In Proceedings of the International Conference on Subsurface Heat Storage in Theory and Practice, Stockholm, Sweden, 6-8 June 1983; pp. 518-523.

27. Hart, G.K.; Whiddon, W.I. Ground Source Heat Pump Planning Workshop; Summary of Proceedings Electric Power Research Institute: Palo Alto, CA, USA, 1984; Volume 2033, p. 12.

28. American Society for Testing and Materials. Soil and Rock (I); ASTM International: West Conshohocken, PA, USA, 2011; ASTM D420-D5876.

29. American Society for Testing and Materials. Standard Test Method for Determination of Thermal Conductivity of Soil and Soft Rock by Thermal Needle Probe Procedure; ASTM International: West Conshohocken, PA, USA, 2008; ASTM D 5334-08.

30. Institute of Electrical and Electronics Engineers. IEEE Guide for Soil Thermal Resistivity Measurements; Institute of Electrical and Electronics Engineers: New York, NY, USA, 1981; IEEE 442.

31. Carslaw, H.S.; Jaeger, J.C. Conduction of Heat in Solids, 2nd ed.; Oxford: London, UK, 1959.

32. Kluitenberg, G.J.; Ham, M.; Bristow, K.L. Error analysis of the heat pulse method for measuring soil volumetric heat capacity. Soil Sci. Soc. Am. J. 1993, 57, 1444-1451. [CrossRef]

33. Peralta, P.K. Investigations on the Behavior of Large Diameter Piles under Long-Term Lateral Cyclic Loading in Cohesionless Soil. Ph.D. Thesis, Leibnitz Universität Hannover, Hannover, Germany, 2010.

34. Shajarati, A.; Sørensen, K.W.; Nielsen, S.K.; Ibsen, L.B. Behaviour of cohesionless soils during cyclic loading. In DCE Technical Memorandum, No. 14; Department of Civil Engineering, Aalborg University: Aalborg, Denmark, 2012.

35. Goldscheider, M. Shakedown and incremental collapse of structures in dry sand bodies. In Proceedings of the Dynamical Methods in Soil and Rock Mechanics, Plastic and Long-Term Effects in Soils 2, Karlsruhe, Germany, 5-16 September 1977; Gudehus, G., Ed.; Balkema: Rotterdam, The Netherlands, 1978; Volume 2 of 3. 